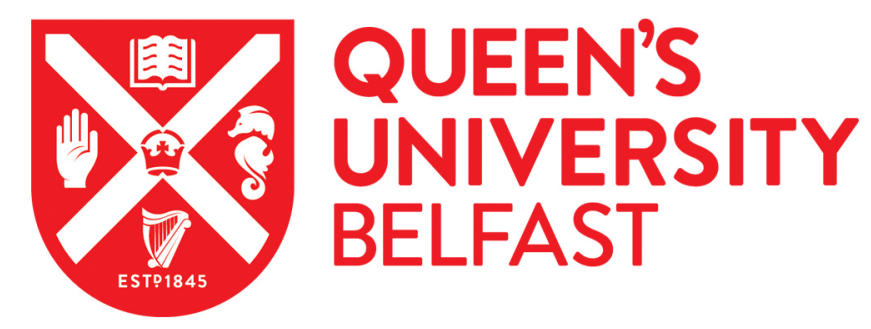

\title{
A Circularly Polarized Antenna in D-Band
}

Gu, C., Bai, L., Cheng, F., \& Yin, S. (2021). A Circularly Polarized Antenna in D-Band. In Proceedings of the 2021 IEEE Texas Symposium on Wireless and Microwave Circuits and Systems: Making Waves in Texas, WMCS 2021 [9493279] (Proceedings of the 2021 IEEE Texas Symposium on Wireless and Microwave Circuits and Systems: Making Waves in Texas, WMCS 2021). Institute of Electrical and Electronics Engineers Inc.. https://doi.org/10.1109/WMCS52222.2021.9493279

\section{Published in:}

Proceedings of the 2021 IEEE Texas Symposium on Wireless and Microwave Circuits and Systems

\section{Document Version:}

Publisher's PDF, also known as Version of record

\section{Queen's University Belfast - Research Portal:}

Link to publication record in Queen's University Belfast Research Portal

\section{Publisher rights}

Copyright 2021 IEEE. This work is made available online in accordance with the publisher's policies. Please refer to any applicable terms of use of the publisher.

\section{General rights}

Copyright for the publications made accessible via the Queen's University Belfast Research Portal is retained by the author(s) and / or other copyright owners and it is a condition of accessing these publications that users recognise and abide by the legal requirements associated with these rights.

Take down policy

The Research Portal is Queen's institutional repository that provides access to Queen's research output. Every effort has been made to ensure that content in the Research Portal does not infringe any person's rights, or applicable UK laws. If you discover content in the Research Portal that you believe breaches copyright or violates any law, please contact openaccess@qub.ac.uk. 


\title{
A Circularly Polarized Antenna in D-Band
}

\author{
Chao $\mathrm{Gu}^{1}$, Lu Bai ${ }^{2}$, Fei Cheng ${ }^{3}$, Shuo Yin ${ }^{4}$ \\ ${ }^{1}$ ECIT Institute, Queens University Belfast, Belfast, UK \\ ${ }^{2}$ School of Computing, Ulster University, Belfast, UK \\ ${ }^{3}$ College of Electronics and Information Engineering, Sichuan University, Chengdu, China \\ ${ }^{4}$ Department of Mechanical and Manufacturing Engineering, Trinity College Dublin, The University \\ of Dublin, Ireland \\ 1'chao.gu@qub.ac.uk, ${ }^{2}$ 1.bai@ulster.ac.uk, ${ }^{3}$ chengfei@scu.edu.cn, ${ }^{4}$ yins@tcd.ie
}

\begin{abstract}
In this paper a $140 \mathrm{GHz}$ circularly polarized antenna is studied. The motivation of this work is to propose a suitable antenna configuration to reduce the subsequent manufacturing cost and complexity. The resultant antenna consists of a circular waveguide feed and a dielectric cover which is used to increase antenna directivity. Numerical study shows that the proposed antenna exhibits a $17 \%$ relative $S_{11}$ bandwidth with a maximum gain of $16 \mathrm{dBi}$. The axial ratio is less than $3 \mathrm{~dB}$ ranging from $130 \mathrm{GHz}$ to 155 GHz.
\end{abstract}

Index Terms-Ceramics, Fabry Perot resonators, additive manufacturing, circular polarization, waveguide, D-band.

\section{INTRODUCTION}

Constant demand to improve wireless system performance results in a need for more spectrum. The emergence of millimetre-wave $(\mathrm{mmW})$ technology as part of the $5 \mathrm{G}$ revolution is a real-world example as the $\mathrm{mmW}$ bands up to $300 \mathrm{GHz}$ are capable of supporting bandwidths up to $2 \mathrm{GHz}$, which is expected to be allocated for the $5 \mathrm{G}$ and beyond.

At present, the $70 / 80 \mathrm{GHz}$ band (E-band) is rapidly gaining popularity, as it enables huge capacity and efficiency improvements for radios access and backhaul applications over 300 meters [1]. Several devices and product generations developed for the E-band is expected to mature for large-scale use during the 2020 to 2030 period. Further efforts are now underway to enable the use of frequencies beyond $100 \mathrm{GHz}$, especially D-band (110 to $170 \mathrm{GHz}$ ) because there are more continuous wide bands with moderate atmospheric absorption. It is anticipated that in D-band fixed wireless service systems, a data rate of higher than $10 \mathrm{Gbit} / \mathrm{s}$ can be achieved provided that some technical impairments, i.e., transmitter noise, signal distortion, are eliminated to maximize modulation for extremely wide channels [2]. Despite the opportunities brought by the $\mathrm{mmW}$ bands, D-band transceivers are facing challenges in terms of transmitted power, packaging, and interconnect. The current trend is towards the use of silicon technologies to achieve high integration and low-cost transceiver modules. For these $\mathrm{mmW}$ modules, antennas are preferred to be integrated and required to be compatible with the silicon process. Onchip antennas are preferred but it is challenging to design high efficiency high gain antennas within a small chip area [3], [4]. Antenna in Package (AiP) or antenna on Package (AoP) has emerged as a cost-effective solution as the antenna is off-chip and implemented on low-cost substrates [5]. However, the performance and cost of the substrate is frequency sensitive, which limits the use of $\mathrm{AiP} / \mathrm{AoP}$ above $100 \mathrm{GHz}$.

It is well known that the metallic waveguide technology is well developed for applications in the $\mathrm{mmW}$ and terahertz ranges. Waveguide approaches are low-loss and precise thus enabling excellent interconnect with active circuits. Traditional waveguide structures are manufactured using CNC machining. The cost for small volume production/prototyping is high. In addition, when waveguide antennas are used as the radiating element, its geometry are limited by the capability of the tools of the $\mathrm{CNC}$ machines. It is desired a flexible and on-demand manufacturing method is employed to achieve faster turnaround and lower cost. Additive manufacturing (AM) is a promising solution and gaining more and more interest in antenna manufacture above $\mathrm{mmW}$ frequencies [5]-[8]. The state-of-the-art AM technologies not only can produce precise all-metal structures but also all-dielectric objects with even a high relative dielectric constant [9], [10]. Therefore, it is possible to realize high-performance antennas with complex geometries at frequencies above $100 \mathrm{GHz}$. in this study we present a hybrid 3D printed antenna which is circularly polarized operating at the 140 $\mathrm{GHz}$ band. Circularly polarized $(\mathrm{CP}) \mathrm{mmW}$ antennas can be used in a wide variety of potential applications such as biomedical imagining and the use of CP antenna can reduce the polarization mismatching loss of wireless communication systems. D-band $\mathrm{CP}$ antennas are less investigated to date because of the challenges in antenna manufacturing. Here a Fabry Perot configuration [11], [12] is employed to achieve gain enhancement over a CP waveguide feed. The antenna parts are compatible with metal and dielectric 3D printing and the resultant antenna 
is compatible with front ends with standard waveguide interface at $\mathrm{D}$ band.

\section{WAVEGUIDE FEED}

To design the CP antenna at D-band by leveraging the capabilities of additive manufacturing technologies, the Fabry-Perot cavity is considered in our design as the superstate and feed can be printed separately. Fig. 1 shows the perspective view of the proposed antenna which consists of a dielectric cover as the superstrate and the waveguide feed as the $\mathrm{CP}$ source. For ease of measurement, the holes are made through each layer to connect to a standard WR6 waveguide flange. The low directivity of the metallic waveguide feed can be enhanced by placing the dielectric cover over the feed while maintaining a satisfactory $\mathrm{CP}$ performance. In the next section we will show the design process of the antenna.

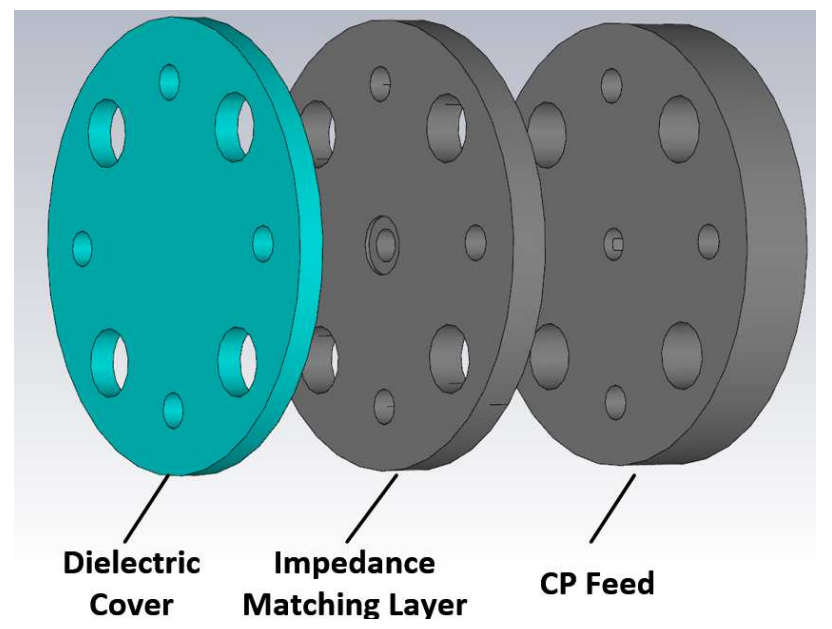

Fig. 1. Configuration of the antenna

The key component for realizing circular polarization of the antenna is the feed with polarization conversion function [13]. The presented polarizer can act as the feed to transmit CP waves and it is suitable to be fabricated using AM. Fig. 2 depicts the schematic view of the feed. For clarity, only the air-filled part of the metal polarizer is shown. The CP is formed at the output of the circular waveguide by introducing a quarter-wave groove cut in the waveguide inner wall when the input port is excited with a linearly polarized wave.

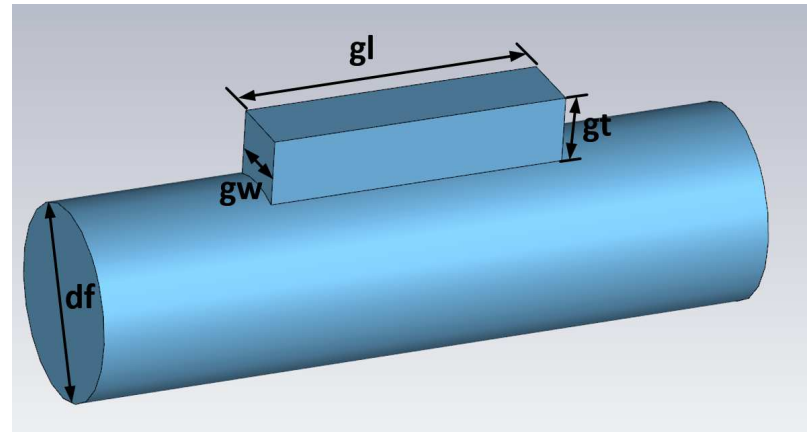

Fig. 2. Schematic view of the air-filled part of metal polarizer

The operating principle of the polarizer is that linearly polarized incident TE11 modes are applied +/-45degree offset with respect to the groove so that the decomposed modes undergo different phase shifts through the groove. After propagating along the polarizer, the amplitudes of the two modes are approximately equal and their phase differ by 90 degrees thereby emanating right/left-hand circularly polarized wave. The simulated reflection coefficient and axial ratio are shown in Fig. 3. The $-10 \mathrm{~dB}$ $S_{11}$ bandwidth ranges from $130 \mathrm{GHz}$ to $155 \mathrm{GHz}$ and the $\mathrm{AR}$ is less than $3 \mathrm{~dB}$ across the band. Thanks to the symmetrical radiating aperture, the radiation patterns of the two principle far-field planes at $140 \mathrm{GHz}$ are almost identical with a realized gain of $7 \mathrm{~dB}$, as shown in Fig. 4 . Moreover, a wide AR beamwidth can be observed at both planes, i.e., $\pm 60^{\circ}$ for $\mathrm{AR} \leq 3 \mathrm{~dB}$.

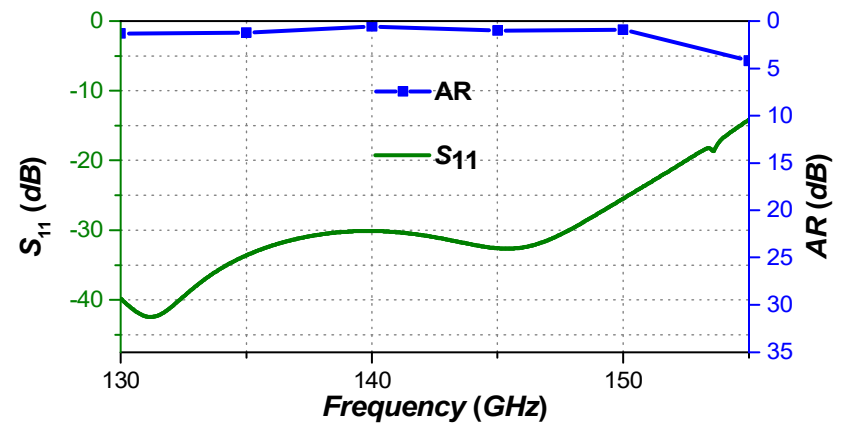

Fig. 3. Simulated reflection coefficient and axial ratio

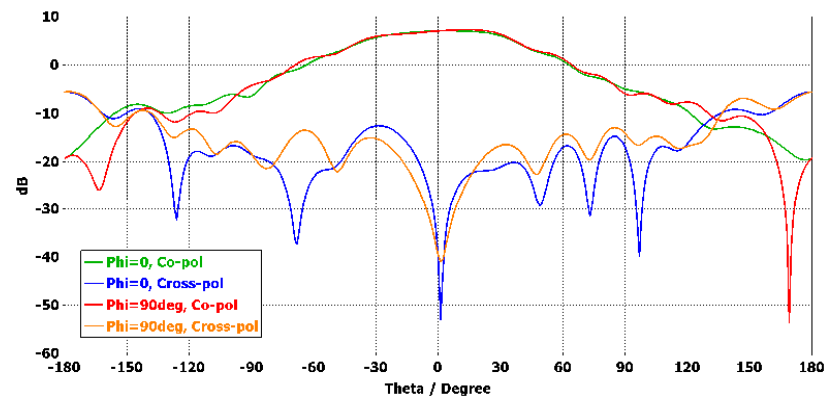


Fig. 4. Simulated radiation patterns at two principle planes at $140 \mathrm{GHz}$

\section{ANTENNA DESIGN}

The CP radiation of the final antenna is achieved by implementing a high permittivity material cover as a planar partially reflecting surface in front of the $\mathrm{CP}$ source. With multiple reflections of the wave inside the formed dielectric-air-metal structure, maximum radiation at broadside direction occurs when the PRS (dielectric layer) has an optimum thickness that yields to in-phase transmitted wave. A dielectric constant of 10.2 is chosen to yield a moderate antenna gain. Also, the whole dielectric cover is designed to be printed using lithography-based ceramic manufacturing technology.

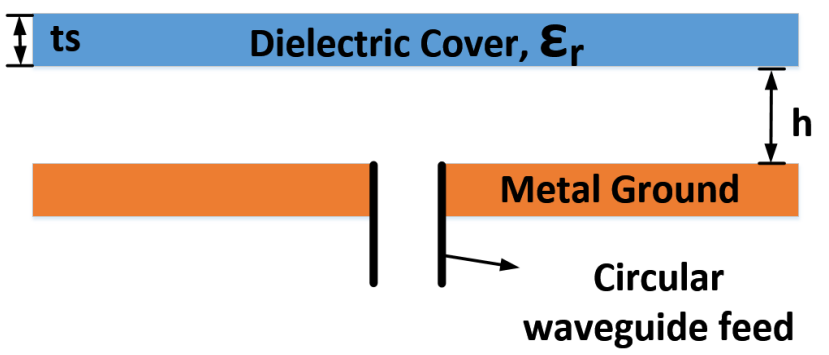

Fig. 5. Side view of the conceptual antenna configuration

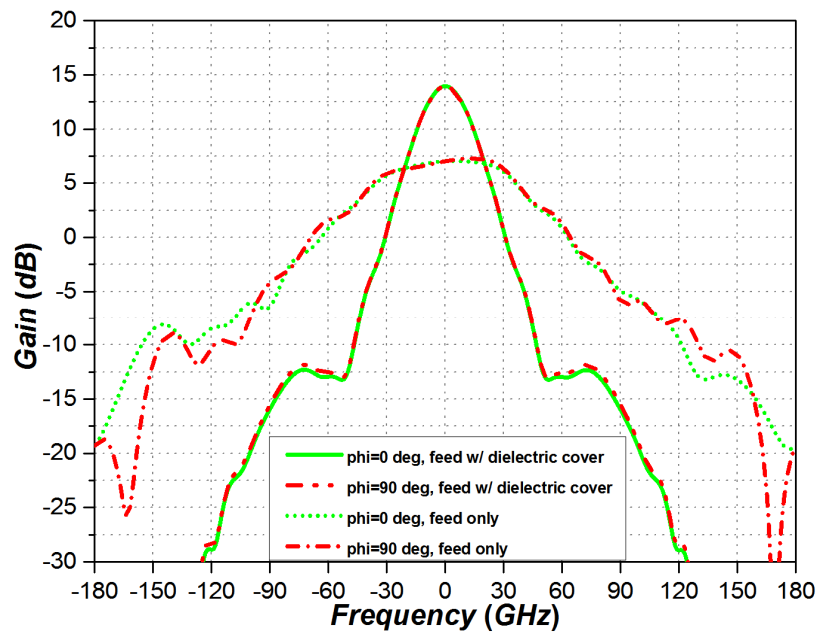

Fig. 6. Simulated gain patterns with/without the dielectric cover at $140 \mathrm{GHz}$

In addition to the thickness of the dielectric cover, the distance between the dielectric and the ground plane should also be optimized with an empirical value of half wavelength at the operating frequency. Fig. 6 shows the simulated gains of the antenna with/without the dielectric cover. It is found that by employing the PRS dielectric layer, the antenna gain can be increased by $8.5 \mathrm{~dB}$. The beam pattern is narrowed due to the gain increase and the side lobe level is excellent, around $20 \mathrm{~dB}$.

The final step is to design an impedance matching layer (IML) for reducing the mismatch between the dielectric cover and the feed. Fig. 7 shows the IML using a stepped circular waveguide transition. The transition has a diameter of $d s$ and the height is $h s$. Table I lists all the parameters of the optimized antenna. It can be noted from Fig. 8 that there is a maximum gain increase of $8.5 \mathrm{~dB}$ at $145 \mathrm{GHz}$ thanks to the introduction of the PRS dielectric cover. More importantly, the presence of the cover has no impact on the AR of the antenna. The simulated 3D radiation pattern at $145 \mathrm{GHz}$ is shown in Fig. 9 .

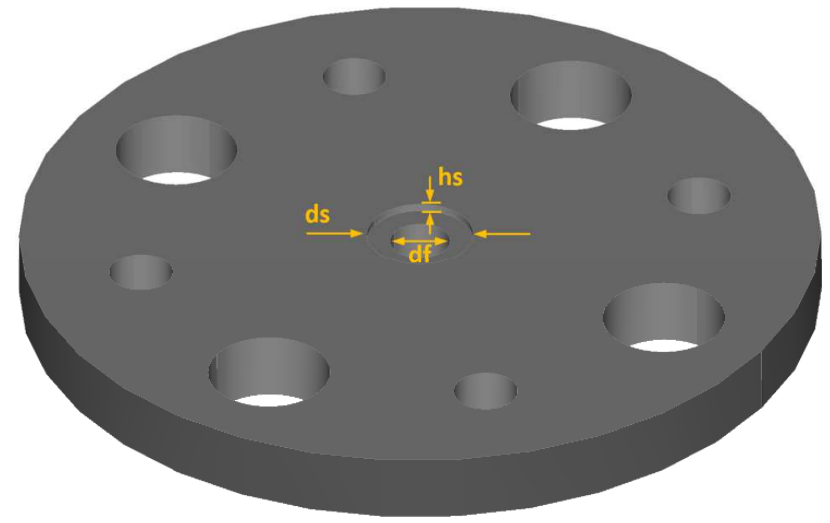

Fig. 7. Schematic view of the impedance matching layer design

TABLE I

Geometric Parameters of the Antenna (Dimension: Mm)

\begin{tabular}{|c|c|c|c|}
\hline gl & gw & df & ts \\
\hline 2.3 & 0.53 & 0.51 & 0.17 \\
\hline$\varepsilon r$ & h & ds & hs \\
\hline 10.2 & 1 & 2.6 & 0.2 \\
\hline
\end{tabular}

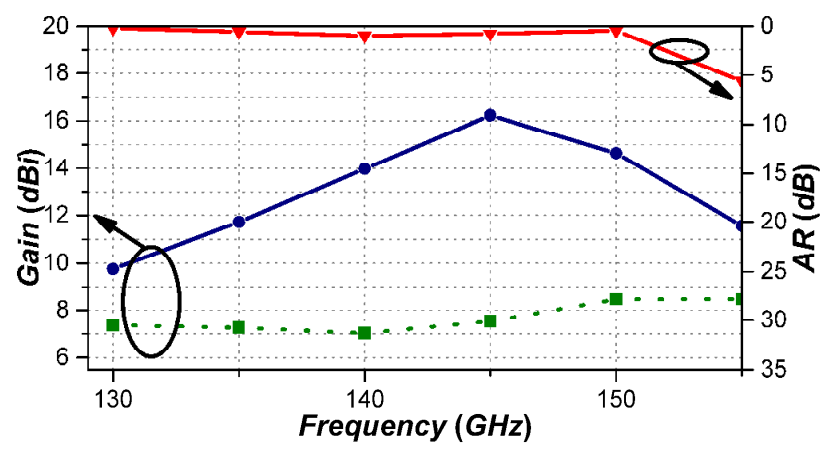

Fig. 8. Simulated gain and AR of the resultant antenna (dotted line: gain of waveguide feed only) 

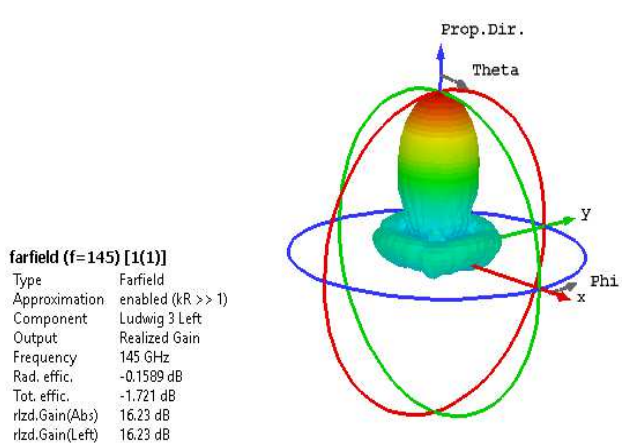

Fig. 9. Simulated 3D radiation pattern at $145 \mathrm{GHz}$

\section{CONCLUSION}

In this work, the Fabry Perot resonant antenna principle is exploited to design a $140 \mathrm{GHz}$ circularly polarized antenna with a directive beam. To be compatible with the current $3 \mathrm{D}$ printing techniques, the antenna feed and gain enhancement superstrate are chosen to be metallic and dielectric, respectively. The dielectric cover placed above the feed is shown to be able to increase the gain by $8.5 \mathrm{~dB}$. The resulting antenna is expected to be printed by Direct Metal Laser Sintering (DMLS) and Stereolithography (SLA) process.

\section{REFERENCES}

[1] Z. Du, E. Ohlmer, K. Aronkyto, J. Putkonen, J. Kapanen, and D. Swist, "5G E-band backhaul system measurements in urban street-level scenarios," in European Microwave Week 2017: "A Prime Year for a Prime Event”, EuMW 2017 - Conference Proceedings; 47th European Microwave Conference, EuMC 2017, 2017, doi: 10.23919/EuMC.2017.8230867.

[2] A. Hirata et al., "120-GHz-band wireless link technologies for outdoor $10-\mathrm{Gbit} / \mathrm{s}$ data transmission," IEEE Trans. Microw. Theory Tech., 2012, doi: 10.1109/TMTT.2011.2178256.

[3] P. Starke, D. Fritsche, S. Schumann, C. Carta, and F. Ellinger, "High-Efficiency Wideband 3-D On-Chip Antennas for Subterahertz Applications Demonstrated at $200 \mathrm{GHz}$," IEEE Trans. Terahertz Sci. Technol., 2017, doi: 10.1109/TTHZ.2017.2698264.

[4] D. Hou, J. Chen, P. Yan, and W. Hong, "A $270 \mathrm{GHz} \times$ 9 Multiplier Chain MMIC with On-Chip DielectricResonator Antenna," IEEE Trans. Terahertz Sci. Technol., 2018, doi: 10.1109/TTHZ.2017.2786027.

[5] R. Xu et al., "A review of broadband low-cost and highgain low-terahertz antennas for wireless communications applications," IEEE Access, 2020, doi: 10.1109/ACCESS.2020.2981393.

[6] C. Gu et al., "Wideband high-gain millimetre/submillimetre wave antenna using additive manufacturing," IET Microwaves, Antennas Propag., 2018, doi: 10.1049/iet-map.2018.5412.

[7] D. Li, S. Gao, C. Gu, J. Wang, D. Song, and X. Li,
"Terahertz polarization reconfigurable segmented helical antenna using additive manufacturing," in 2019 International Applied Computational Electromagnetics Society Symposium-China, ACES 2019, 2019, doi: 10.23919/ACES48530.2019.9060803.

[8] R. Xu et al., " $140 \mathrm{GHz}$ additive manufacturing low-cost and high-gain fabry-perot resonator antenna," in 2020 International Workshop on Antenna Technology, iWAT 2020, 2020, doi: 10.1109/iWAT48004.2020.1570598322.

[9] C. Gu et al., "A D-Band 3D-Printed Antenna," IEEE Trans. Terahertz Sci. Technol., 2020, doi: 10.1109/TTHZ.2020.2986650.

[10] G. Mazingue, B. Byrne, M. Romier, and N. Capet, "3D Printed Ceramic Antennas for Space Applications," in 14th European Conference on Antennas and Propagation, EuCAP 2020, 2020, doi: 10.23919/EuCAP48036.2020.9135312.

[11] G. Von Trentini, "Partially Reflecting Sheet Arrays," IRE Trans. Antennas Propag., 1956, doi: 10.1109/TAP.1956.1144455.

[12] F. Qin et al., "Wideband Circularly Polarized FabryPerot Antenna [Antenna Applications Corner]," IEEE Antennas Propag. Mag., 2015, doi: 10.1109/MAP.2015.2470678.

[13] N. Yoneda, M. Miyazaki, H. Matsumura, and M. Yamato, "A design of novel grooved circular waveguide polarizers," IEEE Trans. Microw. Theory Tech., 2000, doi: 10.1109/22.898996. 